ECONOMICS

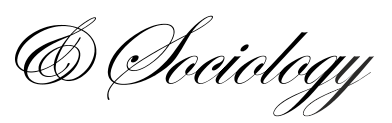

\section{COVID-19 EFFECTS ON FRONTLINE PROFESSIONALS: A PSYCHOLOGICAL ASPECT}

\section{Rita Remeikienè \\ Vilnius University, Law Faculty, \\ Vilnius, \\ Lithuania \\ E-mail: rita.remeikiene@,tf.vu.lt ORCID 0000-0002-3369-485X}

\author{
Albinas Bagdonas \\ Vilnius University, Faculty of \\ Philosophy, Vilnius, \\ Lithuania \\ E-mail:albinas.bagdonas@.fs.vu.lt \\ ORCID 0000-0002-5712-9791
}

Received: December, 2020

1st Revision: May, 2021

Accepted: August, 2021

DOI: $10.14254 / 2071-$

789X.2021/14-3/14

\section{JEL Classification:}

A12, I12, I15

\begin{abstract}
The article aims to investigate the need for psychological help and its availability for professionals working in frontal areas during an emergency situation. A representative study $(\mathrm{N}=1139$; educators, medical staff, social workers, psychologist, and other; 304 respondents from Vilnius district) concluded that the need for psychological services and the intensification of such provision in crisis situations is clear. As a result, the necessary decisions are formed at the state level, which improve the legal regulation of psychological services both at the level of individual agencies and at the interdepartmental level. The authors of the article recommend regulating at least the time norms and costs of psychological services provided in the public sector, as well as regulating the relevant parameters of health care, social or educational services and developing remote psychological services not only for sensitive groups (e.g. children or silver lines), professionals and the general population (especially in the context of social crises), to bring university studies of psychologists more in line with the requirements of the EuroPsy ${ }^{1}$ diploma.
\end{abstract}

Keywords: psychological services, provision of psychological services, front-line professionals, COVID-19 pandemic, Vilnius district.

\title{
Introduction
}

The unprecedented exposure to an unfamiliar Covid-19 infection does not only cause a direct impact on individuals' physical health, but also significantly increases the risk of developing psychological distress and other symptoms of mental disorder caused by a number of factors, starting from the fear of getting sick, feelings of fear, anger, sadness, worry, numbness, or frustration; changes in appetite, energy, desires, and interests, difficulty in sleeping or nightmares, physical reactions, such as headaches, body pains, stomach problems and skin rashes and ending with difficulties to make decisions, burnout, panic, worsening of chronic health problems, worsening of mental health conditions and increased use of tobacco, alcohol and other substances.

\footnotetext{
${ }^{1}$ EuroPsy (or European Certificate in Psychology) is an European standard of education, professional training and competence in psychology set by the European Federation of Psychologists' Associations (EFPA).
} 
Working under extreme conditions, frontline professionals primarily focus on patients' physical state, but their own condition, in particular mental, is often disregarded. As it was noted by Gupta and Sahoo (2020), biopsychological vulnerability of frontline professionals is higher than that of other groups in society due to the effects of such environmental factors as a high risk of contamination, work-related stress, physical discomfort when wearing personal protective measures, and in less developed countries - even the lack of personal protective measures. Despite recognition of the need to care for frontline workers' psychological wellbeing, especially under the extreme conditions of the Covid-19 pandemic (Solomon-Osborne, 2020; Shechter et al., 2020; Cabarkapa et al., 2020; Vizheh et al., 2020; Tomlin, 2020, Dementiev, 2021; Vasylieva, 2021, etc.), the resources that are allocated for its objective evaluation and provision of the necessary assistance are still insufficient. In addition, there are cases when medical professionals or pharmacists avoid seeking psychological help for fear of losing their medical practice licence.

Although emerging literature (Chen et al., 2020; Du et al., 2020; Lu et al., 2020; Lai et al., 2020; Nyashanu et al., 2020, etc.) suggests that mental distress is a very real outcome for frontline professionals, previous studies have mainly focused on the situation in large economies (e.g. China, America, Great Britain, etc.), while the case of small economies has hardly been considered.

The main purpose of this article is to research the psychological state of frontline professionals working under the conditions of the Covid-19 pandemic in a small open economy and provide the recommendations on how to diminish the negative effects of the psychological pressures frontline workers are undergoing. The defined purpose was detailed into the following objectives: 1) based on literature analysis, to review the most common psychological pressures faced by frontline workers; 2) to analyse psychological support measures proposed for frontline workers in previous studies; 3 ) to select and substantiate the methodology of the research; 3) to provide the results of the empirical research on the psychological state of frontline professionals working under the conditions of the Covid-19 pandemic in a small open economy and submit recommendations on how to diminish the negative effects of the psychological pressures frontline workers are undergoing. The research methods include comparative and systematic literature analyses, a questionnaire survey, and a correlation analysis.

\section{Review of the most common psychological pressures faced by frontline workers}

When the world is undergoing the unprecedented situation of the Covid-19 pandemic (Kufel, 2020; Pardal et al., 2020; Dias, et al., 2020; Zinecker et al. 2021), frontline workers are facing immense pressures, and are therefore exposed to physical, mental and social well-being risks. Extreme work conditions can have particularly negative effects on the emotional wellbeing and mental health of these workers. World Health Organisation (2020) indicates the following forms of the negative effects:

- burnout, caused by overwork and/or stress;

- triggering common mental disorders (e.g. depression, anxiety, post-traumatic stress);

- unhealthy behaviours and addictions (e.g. to tobacco, alcohol, sedatives, etc.);

- frequent absence from work or reduced productivity;

- $\quad$ higher risks of suicide.

To develop the effective measures for preventing the above-mentioned adverse effects, it is first appropriate to identify the sources these adverse effects stem from. Based on literature analysis, the most common psychological pressures faced by frontline workers are 
categorised in Table 1, and a more detailed description of the pressures attributed to each category is presented below.

Table 1. Review of the most common psychological pressures faced by frontline workers

Categories Pressures Author(s), year

Fears associated with the Fear of being infected, fear of Tomlin et al., 2020; Du et al., 2020; physical effects of the death Vizheh et al., 2020; Cabarkapa et al., Covid-19 infection 2020; Solomon-Osborne, 2020; Cawcutt et al., 2020

\begin{tabular}{|c|c|c|}
\hline $\begin{array}{l}\text { Pressures caused by } \\
\text { social factors }\end{array}$ & $\begin{array}{l}\text { Stigmatic stereotypes, lack of } \\
\text { social contacts, social exclusion }\end{array}$ & $\begin{array}{l}\text { Solomon-Osborne, 2020; Javadi et al., } \\
\text { 2020; Nyashanu et al., 2020; Gayer- } \\
\text { Anderson et al., } 2020\end{array}$ \\
\hline $\begin{array}{l}\text { Pressures caused } \\
\text { labour factors }\end{array}$ & $\begin{array}{l}\text { Work organising related } \\
\text { stressors, labour force } \\
\text { redistribution, inadequate } \\
\text { patient behaviour }\end{array}$ & $\begin{array}{l}\text { Lu et al., 2020; Lai et al., 2020; Tomlin } \\
\text { et al., 2020; Cabarkapa et al., 2020; } \\
\text { Bolino, 2020; Javadi et al., 2020; } \\
\text { Zhang et al., 2020 }\end{array}$ \\
\hline $\begin{array}{l}\text { Pressures caused } \\
\text { financial factors }\end{array}$ & $\begin{array}{l}\text { Income pressure, financial } \\
\text { obligations }\end{array}$ & $\begin{array}{l}\text { Solomon-Osborne, 2020; "Unicef", } \\
\text { 2020; American Hospital Association, } \\
\text { 2020 }\end{array}$ \\
\hline $\begin{array}{l}\text { Pressures caused } \\
\text { information factors }\end{array}$ & $\begin{array}{l}\text { Fast spread of negative news, } \\
\text { spread of rumours }\end{array}$ & $\begin{array}{l}\text { Vizheh et al., 2020; Javadi et al., 2020; } \\
\text { Tasnim et al., 2020; Cawcutt et al., } \\
2020\end{array}$ \\
\hline
\end{tabular}

Source: compiled by the authors

Fears associated with the physical effects of the Covid-19 infection. This category is mainly characterized by the fear of being infected (Tomlin et al., 2020; Du et al., 2020; Vizheh et al., 2020, etc.) and the fear of death (Cabarkapa et al., 2020; Solomon-Osborne, 2020). Although the risk of acquiring an infection is inherent to the healthcare sector, deviations in proven preventative measures and standards increase the overall risk to frontline healthcare workers (Cawcutt et al., 2020). In Solomon-Osborne's (2020) survey, the refugees in Gambella, Ethiopia, after escaping violent conflict in South Sudan, expressed a genuine fear of being at risk of dying, they were concerned who would take their bodies to their families.

Pressures caused by social factors. The first pressure that should be noted in this category is the fear of stigmatic stereotypes ${ }^{2}$. In the survey of the "Action Against Hunger" humanitarian workers in Ethiopia, Solomon-Osborne (2020) found that the workers are in fear of the stigmatic attitudes related to testing positive for Covid-19. In this case, workers are concerned that being infected with Covid-19, they will be accused of spreading the infection. There is also a fear of the negative attitudes from colleagues and community members, i.e. testing positive can even prevent the workers from returning to work and socializing. In Solomon-Osborne's (2020) opinion, this stigma is usually associated with the lack of information, misinformation, lack of the knowledge about the disease.

In the context of the lack of social contacts, challenges of social distancing and isolation faced by different frontline workers in health and social care sectors were detected by Nyashanu et al. (2020), Gayer-Anderson et al. (2020), etc. Javadi et al. (2020) highlight the mental problems triggered by home quarantine (due to numerous cases of being infected, many frontline workers are required to be home quarantined). In this case, manifestations of

\footnotetext{
${ }^{2}$ The lives of people with mental health conditions are often plagued by stigma. Stigma is a negative stereotype. Stigma is a reality for many people with a mental illness, and they report that how others judge them is one of their greatest barriers to a complete and satisfying life.
} 
panic, claustrophobia can be observed. Self-isolation may even lead to such disorders as insomnia or loss of appetite. The closure of public and private institutions further raises the feeling of social exclusion even if a person is not required to be home quarantined (Javadi et al., 2020).

Pressures caused by labour factors. In this category, work organizing related stressors should be mentioned. Workers' stress can increase due to the growing workload, concentration, responsibility level, time pressure ( $\mathrm{Lu}$ at al., 2020; Tomlin et al., 2020). Additional pressures are experienced when dealing with unclear work objectives, conflicting requirements (Bolino, 2020; Mihalca et al., 2021), when workers deviate from their normal work routines (Javadi et al., 2020), when they lack work equipment and/or personal protective measures (Lai et al., 2020). Cabarkapa et al.'s (2020) research revealed that due to the abovementioned reasons, frontline workers can demonstrate such symptoms as insomnia, anxiety, depression, somatization, and obsessive-compulsive symptoms. These results were also confirmed by Zhang et al. (2020), Vizheh et al. (2020), Xiaoming et al. (2020) and many other authors.

Based on Tomlin et al.'s (2020) research, the stressors related to labour force redistribution must also be included in the category of the pressures caused by labour environment. Labour force redistribution is particularly common in medical institutions where a substantial number of medical professionals get infected and thus are required to be quarantined, which results in severe staffing shortages. Under these circumstances, the remaining part of the staff is redistributed - medical professionals are transferred to other medical institutions in their location or to institutions in other regions. Naturally, this change in location is related to the stress of an unfamiliar territory, working with unfamiliar people in an unfamiliar team, the need to adapt to new policies and procedures.

Minding the direct contacts frontline workers have with patients, it is appropriate to treat inadequate patient behaviour as one of the pressures medical staff are undergoing. Inadequate patient behaviour manifests as verbal insults, accusations levelled against medical staff, etc. (Tomlin et al., 2020).

Pressures caused by financial factors. With changes in the workload, intensity and plans (e.g. working every second week, not working a certain number of days, etc.), and in particular in the case of home quarantine, workers are concerned about their salaries as the basic source of income necessary for family upkeeping (Solomon-Osborne, 2020; American Hospital Association, 2020). This is especially true in single-income families and does not depend on the activity sector, e.g. the necessity to protect salaries of either frontline teachers or healthcare workers was emphasized by "Unicef" (2020). From a financial point of view, significant pressures can also stem from the financial obligations assumed (e.g. loan, mortgage repayment, etc.).

Pressures caused by information factors. According to Vizheh et al. (2020), fast spread of news, especially negative, nowadays may exacerbate public fear, panic and distress, which, in their turn, contribute to poor psychological well-being of frontline workers (Cawcutt et al., 2020). Psychological stress can also be exacerbated by the rumours concerning the etiology, outcomes, prevention and cure of the Covid-19 infection (Javadi et al., 2020; Tasnim et al., 2020). To address the latter issue, frontline workers must be equipped with recent scientific findings and accurate information (Tasnim et al., 2020).

\section{Psychological support measures for frontline workers}

Since prolonged exposure to the above-described pressures may have many harmful consequences on emotional and mental well-being of frontline workers, particular measures can be undertaken to manage this burden. Literature analysis allowed to categorise the main 
support measures proposed for improving psychological well-being and mental balance of frontline workers (see Table 2).

Table 2. Categorisation of the main support measures proposed for improving mental balance of frontline workers

\begin{tabular}{|c|c|c|}
\hline Categories & Support measures & Author(s), year \\
\hline $\begin{array}{l}\text { Organisational } \\
\text { culture/Work } \\
\text { organising }\end{array}$ & $\begin{array}{l}\text { Immediate reaction, managers' example, } \\
\text { regular communication between management } \\
\text { and employees, conditions for employees' } \\
\text { appropriate rest and nutrition, arranging } \\
\text { personal and social spaces, provision of } \\
\text { personal protective measures, mentorship and } \\
\text { knowledge sharing, arranging psychological } \\
\text { counselling }\end{array}$ & $\begin{array}{l}\text { Solomon-Osborne, 2020; Smith, } \\
\text { 2020; Xiao et al., 2020; Vizheh } \\
\text { et al., 2020; Chen et al., 2020; } \\
\text { Liu et al., 2020; Jiang et al., } 2020\end{array}$ \\
\hline $\begin{array}{l}\text { Self-coping } \\
\text { strategies }\end{array}$ & $\begin{array}{l}\text { Exercise, self-guided counselling, special } \\
\text { training, a healthy lifestyle }\end{array}$ & $\begin{array}{l}\text { Cabarkapa et al., 2020; Shechter } \\
\text { et al., 2020; Inchausti et al., } \\
\text { 2020; Chen et al., 2020; World } \\
\text { Health Organisation, 2020 }\end{array}$ \\
\hline Social contacts & $\begin{array}{l}\text { Regular contacts with family and other close } \\
\text { people, support from supervisors and } \\
\text { colleagues }\end{array}$ & $\begin{array}{lrr}\text { Chan and Huak, } & 2004 ; \\
\text { Cabarkapa et al., } & 2020 \text {; } \\
\text { Solomon-Osborne, 2020 } & \end{array}$ \\
\hline $\begin{array}{l}\text { Information } \\
\text { measures }\end{array}$ & $\begin{array}{l}\text { Pro-active dissemination of the information } \\
\text { based on scientific data and expert advice, } \\
\text { provision of optimistic messages, information } \\
\text { about personal safety and hygiene practices }\end{array}$ & $\begin{array}{l}\text { Solomon-Osborne, 2020; Humer } \\
\text { et al., 2020; Zhou, } 2020\end{array}$ \\
\hline
\end{tabular}

Source: compiled by the authors

Organisational culture/Work organising. First of all, to manage the Covid-19 pandemic related situation, the measures must be undertaken at the organisational level. Solomon-Osborne (2020) highlights the necessity of the immediate reaction. To minimize the level of the employee panic, organization managers must respond immediately to the situation when, for instance, employees are taken into quarantine. According to the author, this measure can reduce employees' psychological stress, if organization managers ensure that employees perform their functions without or with a minimal contact with other employees, that the situation of monitored 24/7, and changing conditions dictate what needs to be done and what assistance needs to be provided. The significance of the managers' example is emphasized by Smith (2020) who also notes that regular communication between the managers and employees contributes to improving work organizing and requirements, setting precedents, and receiving the feedback on how employees are coping with the situation.

In addition, Smith (2020) states that managers must encourage employees and create the conditions for their appropriate rest and nutrition. For this purpose, arranging personal and social spaces is recommended. Where possible, food delivery is recommended for both workers in the workplace and those isolating at home (Solomon-Osborne, 2020). According to Smith (2020), this part of the organisational culture helps staff feel more comfortable and thus reduces stress. Provision of personal protective measures (facial masks, protective suits, cleaning materials, hygiene and sterilization products) is compulsory at the organisational level.

Because the lack of the knowledge about the Covid-19 infection and its treatment can be a source of psychological pressure for frontline workers as well as observation of the situation from outside in the case of home isolation, mentorship and knowledge sharing are proposed as valuable support measures. Staff members must be promoted to share their 
insights, discoveries, experiences both directly and remotely (Smith, 2020). A need for greater support through collaboration, training and education was also confirmed by Xiao et al. (2020), Vizheh et al. (2020), Inchausti et al. (2020), Chen et al. (2020), etc.

When monitoring employees' behaviour, managers must inquire whether employees need professional psychological counselling and at request arrange such counselling (an arriving, part-time, full-time or externally available psychologist) (Smith, 2020). Jiang et al. (2020) emphasise the importance of involvement of a psychologist/psychiatrist in an organisation (onsite psychotherapy). In this context, Liu et al. (2020) and Vizheh et al. (2020) even talk about the indispensability of psychological counselling.

Self-coping strategies. Apart from a wide variety of the organisational support measures, frontline workers can build their acceptance, resilience, active coping and positive framing through self-coping strategies (Cabarkapa et al., 2020). Shechter et al.'s (2020) research revealed that among 657 American healthcare workers, exercise was the most commonly used coping strategy (59\%), and access to an individual therapist with online selfguided counselling $(33 \%)$ generated a wide interest. Having researched the issues of assisting frontline health professionals, Inchausti et al. (2020) and Chen et al. (2020) note that the special training can substantially help them learn to manage their emotional reactions to work situations, overcome anxiety and fear of contagion, prevent burnout, and thus raise their psychological resilience. World Health Organisation (2020) proposes maintaining a healthy lifestyle, which means that frontline workers can contribute to both their physical and mental health by maintaining a healthy diet, staying well-hydrated, having a rest during any downtime at work, getting enough sleep between shifts, avoiding unhealthy coping behaviours (e.g. using, tobacco, alcohol, etc.), doing simple actions that bring joy, practicing breathing, muscle relaxation, grounding and mindfulness techniques, and most important knowing their limits.

Maintaining social contacts. A substantial part of authors (Chan and Huak, 2004; Cabarkapa et al., 2020; Solomon-Osborne; 2020, etc.) emphasize the significance of maintaining social contacts. Cabarkapa et al. (2020) found that support from supervisors and colleagues is a significant negative predictor for psychiatric symptoms. Also, to diminish psychological stress, even persons who are required to be quarantined need to be able to keep in touch with their family members and other close people. Solomon-Osborne (2020) notes that this measure is significant not only because close people can provide psychological support to vulnerable people, but it is also important for those in isolation to know that their family and relatives know about what is happening to them and in their lives. Where possible, the measures (e.g. technical equipment, location, space, etc.) to facilitate such social contacts and ensure privacy of communication can be provided by organisations, in particularly those where the persons in isolation work.

Information measures. To deal with the mental pressure caused by the stigmatic approach to the infection and the infected, which particularly painfully affects frontline workers, it is essential to pro-actively disseminate the information based on scientific data and expert advice, emphasize that catching the infection is not a person's fault, provide optimistic messages that most people fully recover from the infection and are no longer contagious after testing negative (Solomon-Osborne, 2020). Humer et al. (2020) state that information can help to normalize the reaction of different social groups to stress. Mass media channels (e.g. television, radio, internet, etc.) can be invoked to disseminate the information on what personal safety and hygiene practices can help one protect against infection, and thus contribute to reducing the overall level of social anxiety (Zhou, 2020). 


\section{Methodology of the survey}

\subsection{Survey and respondents}

To achieve the intended objectives, the quantitative research was conducted by employing an online survey. Representatives of various professions (educators, medical staff, social workers, psychologist and other) in the face of the COVID-19 pandemic were sent emails with an invitation to participate in the survey and express personal views. Respondents' contacts were extracted by searching for publically available information on the websites of public authorities and private companies. All publically available target contacts were addressed with e-mails inviting to participate in the survey. The survey was being conducted from October 30 to November 20, 2020, i.e. during the second wave of the pandemic in Lithuania.

The data were obtained from 1139 respondents: 968 female and 168 male. Distribution of the respondents by age was as follows: the respondents aged 21-29 accounted for 20.7\%, the respondents aged 30-39 - for 20.4\%, the respondents aged 40-49 - for $22.3 \%$, the respondents aged 50-59 - for $25.9 \%$, and the respondents aged $60+-$ for $10.7 \%$ of the total number of survey participants (respondents' age ranged from 21 to 72). The geographical distribution of the respondents covered all Lithuanian districts (from 4 respondents in Taurage district to 304 respondents in Vilnius district; the number of the respondents representing most other districts amounted to several tens). The majority of the respondents indicated having higher education (84.3\%). $13.3 \%$ of the respondents indicated having higher nonuniversity education, and only $2.4 \%$ - secondary/vocational education. Distribution of the respondents by the qualification acquired through education or work experience was as follows: teachers - 18.6\%; health care professionals - 23\%; social workers - 22.2\%; pharmacists $-8.4 \%$; custom officers $-6.3 \%$; psychologists $-5.3 \%$; education support professionals $-2.8 \%$; business people $-2 \%$; other qualifications $-3.8 \%$. For further analysis, the initial list of qualifications was shortened by attributing some related qualifications to a few larger groups: 1) educators $(244)$; 2) medical staff $(358)$; 3) social workers $(253) ; 4)$ psychologists (60); 5) other professionals (138).

Because one of the objectives of this study was to obtain the comprehensive data on the situation of the COVID-19 frontline professionals, they were also asked a question about the financial condition of their families. The answers were a bit surprising: the respondents declared earning sufficient income in the context of Lithuania (answering the survey questions, the respondents were not inclined to exaggerate their income; on the other hand, when participating in surveys, respondents are likely to diminish their income). Currently, the minimum consumption requirement (MCR) established in Lithuania amounts to 257 Eur for the first person in a family (and slightly lower amounts are established for the second and other persons in a family). In our sample, out of 1107 respondents who answered the question about their income, only $2.6 \%$ declared that their income per one family member amounts to 266 Eur or less. Across the sample, the average monthly income per family member amounts to 827.3 Eur: the highest average, amounting to 1055.16 Eur, was estimated for health care professionals, while the lowest, amounting to 623.9 Eur, was estimated for social workers; the average monthly income per family member in educators' families amounted to 687 Eur.

\subsection{Questionnaire}

The professionals were asked about their experience concerning the effects of the pandemic, changes in their psychological well-being, personal opinions about the society 
undergoing the pandemic, mental condition of Lithuanian people during the pandemic and the need for psychological services in a society or a community. The questionnaire consisted of three main parts: 1) the questions about personal experience and well-being assessment (changes in psychological well-being, use of psychological services, the need to receive psychological services); 2) assessment of the changes in public psychological well-being, the need for psychological services in society, evaluation of the psychological services provided; 3) socio-demographic questions (age, gender, education, marital status, qualification by education or work experience, work position, assessment of personal financial situation). The survey included various types of questions: open-ended questions, semi-open-ended questions and close-ended questions. This article presents only the results of the quantitative analysis.

\subsection{Data processing}

Statistical analysis of the data was performed by employing the SPSS-26 software package: the analysis covered estimation of answer frequencies, relationship between particular variables (Pearson correlation coefficients) as well as several dimensions of means and answer frequencies (see the Results section). To identify the differences between crossgroup means, one-way analysis of variance (ANOVA) was applied, while the differences in answer frequencies were identified by employing $\chi 2$ criterion.

\section{Conducting research and results}

\subsection{View on the impact of the COVID-19 pandemic on the respondents}

Several questions were designed to assess the potential impact of the pandemic on the respondents themselves. At first, the respondents were asked whether they experienced any changes in their well-being during the pandemic. Over 75 percent of the total sample indicated that their well-being worsened (see Table 3). For health care professionals, this number amounted to 80 percent. The cross-group differences were found to be statistically significant.

Table 3. Changes in the well-being of different professionals experienced during the pandemic (percentage of the respondents who indicated having experienced any changes in their well-being)

\begin{tabular}{|c|c|c|c|c|c|c|c|}
\hline $\begin{array}{l}\text { Changes in professionals' } \\
\text { well-being }\end{array}$ & $\begin{array}{c}\text { Total } \\
(\mathrm{n}=\mathbf{1 0 5 3})\end{array}$ & $\begin{array}{l}\text { Educators } \\
(\mathrm{n}=244)\end{array}$ & $\begin{array}{l}\text { Medical } \\
\text { staff } \\
(\mathrm{n}=358) \\
\end{array}$ & $\begin{array}{c}\text { Social } \\
\text { workers } \\
(\mathrm{n}=253) \\
\end{array}$ & $\begin{array}{l}\text { Psychologists } \\
\qquad(\mathrm{n}=60)\end{array}$ & $\begin{array}{l}\text { Others } \\
(\mathrm{n}=138)\end{array}$ & $\chi^{2}$ \\
\hline $\begin{array}{l}\text { Well-being remained the } \\
\text { same as before the } \\
\text { pandemic }\end{array}$ & 20.7 & 19.3 & 17.3 & 19.4 & 25.0 & 32.6 & \multirow{7}{*}{0.000} \\
\hline $\begin{array}{l}\text { Well-being slightly } \\
\text { worsened }\end{array}$ & 43.1 & 44.7 & 39.1 & 46.2 & 50.0 & 42.0 & \\
\hline Well-being worsened & 27.0 & 24.6 & 33.5 & 26.5 & 18.3 & 18.8 & \\
\hline $\begin{array}{l}\text { Well-being significantly } \\
\text { worsened }\end{array}$ & 6.8 & 9.0 & 7.0 & 7.1 & 1.7 & 4.3 & \\
\hline $\begin{array}{l}\text { Well-being slightly } \\
\text { improved }\end{array}$ & 1.0 & 0.0 & 1.4 & 0.8 & 5.0 & 0.7 & \\
\hline Well-being improved & 0.9 & 1.6 & 1.4 & 0.0 & 0.0 & 0.7 & \\
\hline $\begin{array}{l}\text { Well-being significantly } \\
\text { improved }\end{array}$ & 0.4 & 0.8 & 0.3 & 0.0 & 0.0 & 0.7 & \\
\hline
\end{tabular}

Source: compiled by the authors 
Another question concerning the effects of the COVID-19 pandemic on the respondents was more specific: the respondents were asked if they have felt any direct effects since March 2020. 50 percent of the respondents did not feel any direct effects, one-fifth were required to be quarantined, and another one-fifth reported a decline in their income. Although the majority of the respondents did not indicate any direct effects $(49.6 \%)$, several tens were infected with COVID-19, a couple of hundred reported a decline in their income, and the same number were required to be quarantined (see Table 6). At the same time, nearly $6 \%$ of the respondents indicated that their income increased (in particular for the medical staff). No statistically significant differences were found when comparing the answer groups concerning COVID-19 infection, a decline in income, requirement to be quarantined and a job loss (see Table 4).

Table 4. Direct effects of the COVID-19 pandemic reported by various professionals (percentage of the respondents)

\begin{tabular}{lccccccc}
\hline \multicolumn{1}{c}{ Effect } & $\begin{array}{c}\text { Total } \\
(\mathbf{n =} \\
\mathbf{1 0 5 3})\end{array}$ & $\begin{array}{c}\text { Educators } \\
(\mathrm{n}=244)\end{array}$ & $\begin{array}{c}\text { Medical } \\
\text { staff } \\
(\mathrm{n}=358)\end{array}$ & $\begin{array}{c}\text { Social } \\
\text { workers } \\
(\mathrm{n}=253)\end{array}$ & $\begin{array}{c}\text { Psychologists } \\
(\mathrm{n}=60)\end{array}$ & $\begin{array}{c}\text { Others } \\
(\mathrm{n}=138)\end{array}$ & $\chi^{2}$ \\
\hline Was sick & $\mathbf{3 . 6}$ & 2.9 & 4.2 & 4.3 & 1.7 & 2.9 & 0.740 \\
\hline $\begin{array}{l}\text { Was not sick, } \\
\text { but was required } \\
\text { to stay } \\
\text { quarantined }\end{array}$ & $\mathbf{2 0 . 6}$ & 16.4 & 24.6 & 18.6 & 20.0 & 21.7 & 0.143 \\
\hline $\begin{array}{l}\text { A family } \\
\text { member, a close } \\
\text { friend was sick }\end{array}$ & $\mathbf{1 3 . 7}$ & 9.0 & 23.7 & 6.7 & 11.7 & 9.4 & 0.000 \\
\hline Lost a job & $\mathbf{1 . 1}$ & 0.8 & 1.4 & 2.0 & 0.0 & 0.0 & 0.369 \\
\hline Income declined & $\mathbf{2 0 . 6}$ & 20.1 & 18.4 & 19.8 & 30.0 & 24.6 & 0.215 \\
\hline $\begin{array}{l}\text { Income } \\
\text { increased }\end{array}$ & $\mathbf{5 . 9}$ & 1.2 & 12.6 & 3.2 & 3.3 & 2.9 & 0.000 \\
\hline $\begin{array}{l}\text { Did not feel any } \\
\text { effects }\end{array}$ & $\mathbf{4 9 . 6}$ & 59.8 & 39.7 & 53.4 & 50.0 & 50.0 & 0.000 \\
\hline
\end{tabular}

Source: compiled by the authors

Although more than two-thirds of the respondents reported the impact of the pandemic on their well-being, a similar number selected the answer that they did not seek help from a psychologist or a psychiatrist and did not need to do so. Nearly a quarter of the respondents indicated that they had intentions to seek help, 5 percent noted that they sought help once / more than once, and almost the same number reported that they use the services of mental health professionals on a regular basis (see Table 5).

We tried to obtain more detailed information about the abnormalities of mental wellbeing experienced by different professionals and included a 7-point evaluation scale question How often do you feel the symptoms of such conditions? The following conditions were reported: a) a specific fear of the loss of their or their loved ones' health, work or income; b) stress; c) anxiety; d) depression; e) sleep disorders; f) feeling of constant fatigue; g) feeling of boredom; h) professional burnout (feeling of disappointment); i) others (see Table 6). 
Table 5. Percentage of the frequency of the responses provided by different professionals concerning seeking help from a psychologist or a psychiatrist during the pandemic and statistical significance of cross-group differences

\begin{tabular}{|c|c|c|c|c|c|c|c|}
\hline Effect & $\begin{array}{c}\text { Total } \\
(\mathbf{n}= \\
1053)\end{array}$ & $\begin{array}{l}\text { Educators } \\
(\mathrm{n}=244)\end{array}$ & $\begin{array}{c}\text { Medical } \\
\text { staff } \\
(\mathrm{n}= \\
358) \\
\end{array}$ & $\begin{array}{c}\text { Social } \\
\text { workers } \\
(n=253)\end{array}$ & $\begin{array}{l}\text { Psychologists } \\
\quad(\mathrm{n}=60)\end{array}$ & $\begin{array}{c}\text { Others } \\
(\mathrm{n}=138)\end{array}$ & $\chi^{2}$ \\
\hline $\begin{array}{l}\text { Did not seek } \\
\text { and did not need } \\
\text { to do so }\end{array}$ & 67.0 & 68.4 & 63.1 & 68.0 & 51.7 & 79.7 & \multirow{5}{*}{0.000} \\
\hline $\begin{array}{l}\text { Had such } \\
\text { intentions }\end{array}$ & 23.6 & 26.6 & 26.8 & 24.1 & 15.0 & 13.0 & \\
\hline Sought once & 2.3 & 2.0 & 1.7 & 4.0 & 1.7 & 1.4 & \\
\hline $\begin{array}{l}\text { Sought more } \\
\text { than once }\end{array}$ & 2.5 & 2.0 & 3.1 & 2.0 & 3.3 & 2.2 & \\
\hline $\begin{array}{l}\text { Use services of } \\
\text { mental health } \\
\text { professionals on } \\
\text { a regular basis }\end{array}$ & 4.6 & 0.8 & 5.3 & 2.0 & 28.3 & 3.6 & \\
\hline
\end{tabular}

Source: compiled by the authors

The evaluation scales included the following alternatives: 1) never; 2) very rarely; 3 ) rarely; 4) sometimes; 5) often; 6) very often; 7) constantly. The evaluation scales across the sample were characterized by a strong consistency coefficient (Cronbach's alpha) -0.85 . Means, their standard deviations and statistical significance of the cross-group mean differences (estimated by applying one-way analysis of variance (ANOVA)) are presented in Table 5. All respondents across the sample indicated the following symptoms of their mental condition: stress (mean 4.66), specific fears of the loss of their or their loved ones' health, work or income (mean 4.44) and constant fatigue (mean 4.33). It is interesting to note that the respondents representing different professions are least likely to feel the signs of depression (mean 2.62; for medical staff, the mean was slightly higher than for other groups and amounted to 2.83). Similar tendencies were revealed by the answer frequency analysis. The percentage values of the aggregate answers "sometimes + often + very often + constantly" representing the changes in the respondents' mental well-being are presented below:

- $\quad$ specific fears $-74.7 \%$ (educators $-80 \%$ );

- $\quad$ stress $-80 \%$ (medical staff $-87.3 \%$ );

- $\quad$ anxiety $-71 \%$ (educators $-74.3 \%$ );

- $\quad$ depression $-23.6 \%$ (medical staff $-30.9 \%$ );

- $\quad$ sleep disorders $-47.7 \%$ (educators $-52 \%$, medical staff $-50.5 \%$ );

- $\quad$ constant fatigue $-71.7 \%$ (medical staff $-80.7 \%$ );

- $\quad$ feeling of boredom $-26.3 \%$ (medical staff $-33.7 \%$ )

- $\quad$ professional burnout $-61.5 \%$ (medical staff $-67 \%$ ). 
Table 6. Means (M), standard deviations (SD) and statistical significance of cross-group differences (p) estimated for the changes in different professionals' mental well-being (based on a 7-point evaluation scale)

\begin{tabular}{|c|c|c|c|c|c|c|c|c|c|}
\hline Profession & & 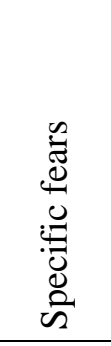 & 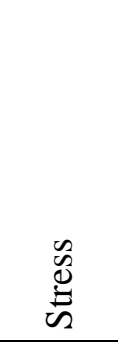 & 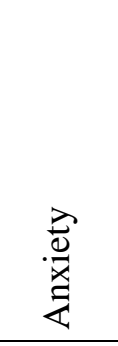 & 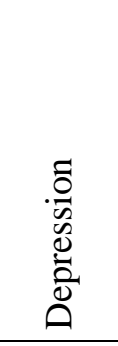 & 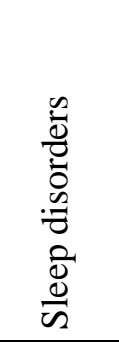 & 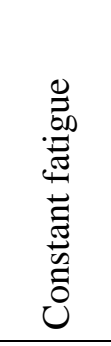 & 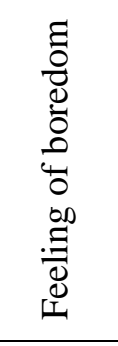 & 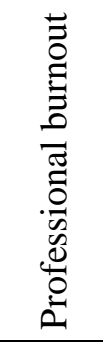 \\
\hline \multirow{2}{*}{$\begin{array}{l}\text { Educators } \\
(\mathrm{n}=191)\end{array}$} & $\mathrm{M}$ & 4.58 & 4.63 & 4.40 & 2.72 & 3.71 & 4.37 & 2.73 & 3.98 \\
\hline & $\mathrm{SD}$ & 1.44 & 1.48 & 1.47 & 1.56 & 1.49 & 1.47 & 1.39 & 1.51 \\
\hline \multirow{2}{*}{$\begin{array}{l}\text { Medical staff } \\
(\mathrm{n}=285)\end{array}$} & $\mathrm{M}$ & 4.37 & 4.99 & 4.46 & 2.83 & 3.82 & 4.65 & 3.05 & 4.35 \\
\hline & $\mathrm{SD}$ & 1.40 & 1.33 & 1.48 & 1.56 & 1.56 & 1.476 & 1.48 & 1.56 \\
\hline \multirow{2}{*}{ Social workers $(n=202)$} & $\mathrm{M}$ & 4.59 & 4.53 & 4.28 & 2.46 & 3.57 & 4.15 & 2.56 & 3.82 \\
\hline & SD & 1.31 & 1.34 & 1.37 & 1.34 & 1.47 & 1.34 & 1.31 & 1.43 \\
\hline \multirow{2}{*}{$\begin{array}{l}\text { Psychologists } \\
(\mathrm{n}=42)\end{array}$} & $\mathrm{M}$ & 3.83 & 4.55 & 4.12 & 2.40 & 3.10 & 4.45 & 2.50 & 3.33 \\
\hline & SD & 1.17 & 1.45 & 1.27 & 1.06 & 1.51 & 1.42 & 1.27 & 1.41 \\
\hline \multirow{2}{*}{$\begin{array}{l}\text { Others } \\
(\mathrm{n}=90)\end{array}$} & $\mathrm{M}$ & 4.31 & 4.03 & 3.92 & 2.23 & 3.38 & 3.59 & 2.93 & 3.83 \\
\hline & SD & 1.42 & 1.44 & 1.40 & 1.38 & 1.35 & 1.32 & 1.13 & 1.55 \\
\hline \multirow{2}{*}{$\begin{array}{l}\text { Total } \\
(\mathrm{n}=\mathbf{8 1 0})\end{array}$} & $\mathbf{M}$ & 4.44 & 4.66 & 4.32 & 2.62 & 3.64 & 4.33 & 2.81 & 4.02 \\
\hline & SD & 1.39 & 1.41 & 1.44 & 1.47 & 1.50 & 1.45 & 1.38 & 1.53 \\
\hline $\begin{array}{l}\text { Statistical significance of } \\
\text { cross-group differences }\end{array}$ & $\mathrm{p}$ & 0.007 & 0.025 & 0.002 & 0.003 & 0.011 & 0.000 & 0.001 & 0.000 \\
\hline
\end{tabular}

Source: compiled by the authors

It should be noted that the medical staff reported very strong stress and professional burnout. Two-thirds of the medical staff often or continuously experience the feeling of professional burnout, which is, actually, happening during the period of emphasizing the significance of their profession and financial promotion. Thus, the findings indicate a particularly heavy workload and daily encounter with the facts of death.

\subsection{Assessment of the impact of the COVID-19 pandemic on the society and community}

Given that the respondents need to communicate with their customers (patients, students, social service recipients), they were asked whether the mental condition of their customers could have changed during the pandemic compared to the situation before the pandemic. The respondents answered this question very unanimously: across the sample, the answer Worsened was provided by $94.1 \%$ of the respondents, and slightly ranged for different groups of professionals - from $90 \%$ (other respondents) to $96.1 \%$ (medical staff). No statistically significant cross-group differences were found $(\chi 2>0.05)$.

When answering the more specific question, i.e. when indicating which aspects of public mental well-being were most significantly affected, the respondents expressed the opinions which differed statistically significantly, except for assessment of boredom which received only $14.5 \%$ of the positive answers. All the respondents emphasized increased 
anxiety (with overall positive response rate equal to $83.2 \%$ and group assessment ranging from $71 \%$ (other respondents) to $98 \%$ (psychologists)) (see Table 7).

Table 7. Assessment of the impact of the COVID-19 pandemic on public mental well-being provided by different professionals (frequencies of positive answers as a percentage and statistical significance of cross-group differences $(\chi 2))$

\begin{tabular}{lccccccc}
\hline \multicolumn{1}{c}{ Effects } & $\begin{array}{c}\text { Total } \\
(\mathbf{n =}= \\
\mathbf{1 0 5 3})\end{array}$ & $\begin{array}{c}\text { Educators } \\
(\mathrm{n}=244)\end{array}$ & $\begin{array}{c}\text { Medical } \\
\text { staff } \\
(\mathrm{n}= \\
358)\end{array}$ & $\begin{array}{c}\text { Social } \\
\text { workers } \\
(\mathrm{n}=253)\end{array}$ & $\begin{array}{c}\text { Psychologists } \\
(\mathrm{n}=60)\end{array}$ & $\begin{array}{c}\text { Others } \\
(\mathrm{n}=138)\end{array}$ & $\chi^{2}$ \\
\hline $\begin{array}{l}\text { Specific } \\
\text { fears }\end{array}$ & $\mathbf{5 3 . 1}$ & 50.4 & 59.0 & 49.6 & 45.6 & 51.6 & 0.09 \\
\hline Stress & $\mathbf{6 6 . 3}$ & 58.8 & 72.4 & 70.4 & 78.9 & 49.2 & 0.000 \\
\hline Anxiety & $\mathbf{8 3 . 2}$ & 78.8 & 87.8 & 83.8 & 98.2 & 71.0 & 0.000 \\
\hline Depression & $\mathbf{3 3 . 7}$ & 30.5 & 45.1 & 26.7 & 42.1 & 17.7 & 0.000 \\
\hline $\begin{array}{l}\text { Sleep } \\
\text { disorders }\end{array}$ & $\mathbf{3 5 . 0}$ & 31.9 & 45.9 & 30.8 & 43.9 & 14.5 & 0.000 \\
\hline Boredom & $\mathbf{1 4 . 5}$ & 11.9 & 16.0 & 14.2 & 15.8 & 15.3 & 0.742 \\
\hline $\begin{array}{l}\text { Anger and } \\
\text { aggression }\end{array}$ & $\mathbf{5 4 . 9}$ & 44.7 & 62.8 & 59.6 & 43.9 & 47.6 & 0.000 \\
\hline $\begin{array}{l}\text { Increased } \\
\text { alcoholism }\end{array}$ & $\mathbf{2 2 . 8}$ & 11.5 & 26.7 & 32.5 & 21.1 & 14.5 & 0.000 \\
\hline Source: & & & &
\end{tabular}

Source: compiled by the authors

\subsection{Evaluation of existing psychological services and the need for such services}

Some questions were designed for evaluation of the quality of psychological services and the need for such services. Although the data in Table 6 indicate that the respondents are not frequent patients of psychologists, they were active in evaluating the quality of and the need for these services. The respondents were also asked about the (un)availability of psychological services. Although the respondents provided comparatively different answers, the general tendencies were that psychological services: 1) are hardly available $(32.6 \%) ; 2$ ) are available $(27.9 \%)$; 3) are of poor quality $(24.6 \%) ; 4)$ are characterized by unorganized costs $(23 \%)$. Frequency of the answers proposing that psychological services are not needed was less than $1 \%$ (provided by some respondents representing medical staff, and some respondents representing educators).

In a logical sequence, the following question was asked: Does your experience of the COVID-19 pandemic suggest that provision of psychological services should change? (you can mark more than one answer). The answers revealed the following tendencies: 1) service accessibility should be increased $(58.4 \%$; medical staff $-69.3 \%)$; 2 ) service quality needs to be improved $(42.1 \%$; social workers $-47.3 \%)$; 3) networks for remote service provision should be developed (41.5\%; psychologists $-51.7 \%$; medical staff $-49.2 \%$ ).

Concerning the preferable location of receiving psychological services, the most frequent answer was a private clinic (52\%; psychologists $-70 \%)$, followed by outpatient clinics $(18.6 \%$; educators $-27.9 \%)$ and voluntary organizations $(20.4 \%$; social workers $26.1 \%)$. 


\section{Discussion}

Although the number of surveys similar to the one we are presenting has increased significantly and will continue to increase, each of them also has its own specific characteristics, which are determined by the specific combinations of respondents and applied variables. The participants in this study were not ordinary citizens in general, but several categories of professionals at the forefront of the COVID-19 pandemic: physicians, educators, social workers, and psychologists. The purpose of the survey: to optimize psychological services, the need for which usually increases in crisis situations. They are needed by crisis management professionals, other professionals and the general public. With this in mind, that general goal was directed in three directions: 1) the well-being of the specialists in the leading positions and the whole situation; 2) seeing them as ordinary citizens surviving the COVID19 pandemic; 3) what is the need for psychological services and how are they organized. This study is exploratory but specific: it puts an emphasis on possible changes in mental status due to the COPVID-19 pandemic and the organization of psychological services. As the study is based on a statistical analysis of the subjective self-esteem of the respondents, it is difficult to make any deeper theoretical insights. Therefore, here we will limit ourselves to summarizing the factual material in the above three aspects.

Health professionals are involved in the direct fight against the SARS-Cov-2 virus. Educators, social workers and other professionals are only at higher risk of contracting the virus in the area and continuing their professional activities in changed circumstances. Everyone, especially health professionals, is much more sensitive to changes in the mental state of both themselves and ordinary people.

Only every second respondent felt the specific consequences of the pandemic, although another issue identifying specific changes in the situation is increasing. From Graph 1 we see that in 4 cases out of 7 listed, more than 50\% respondents indicate deterioration. Responses such as "annoyance", "anger", and "headaches" were common among the "other" responses.

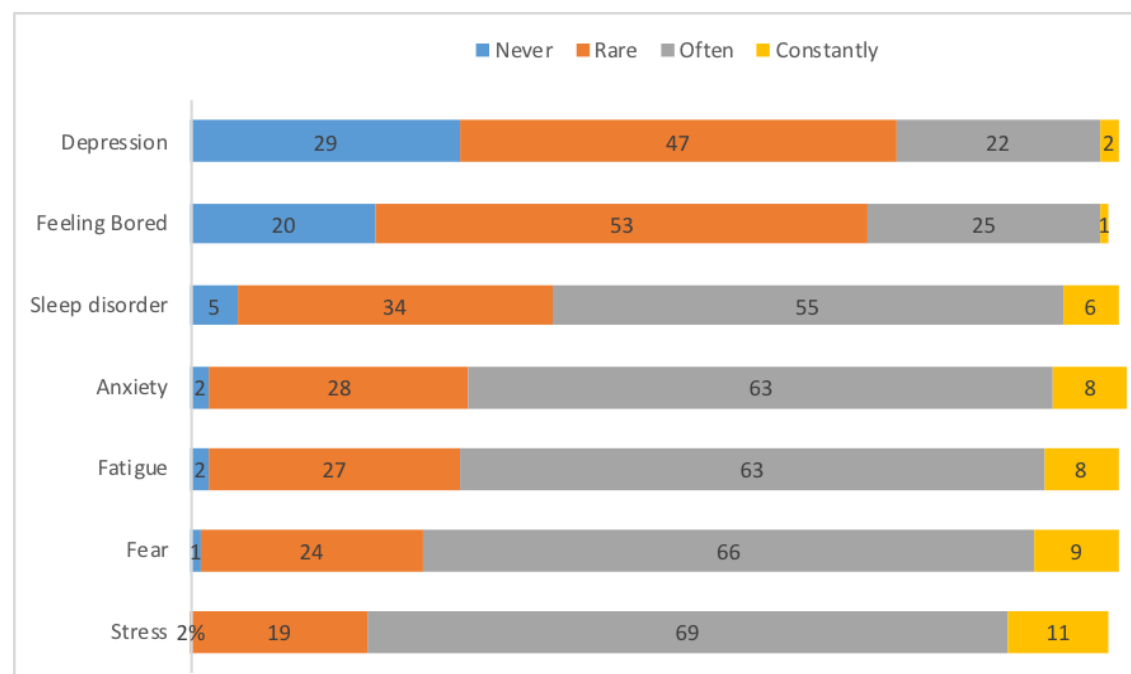

Graph. 1 Frequencies of respondents' answers to the question about changes in mental states due to a pandemic, percent

Source: compiled by the authors

Observing people for such non-compliance with the established order makes the annoyance and anger of professionals (especially doctors) understandable (what we observe 
now in the public sphere, when the health care system is running out of its potential). Summarizing the results related to the personal psychological well-being of professionals, it can be seen that the assessment of psychological health is closely related to a person's age and profession. The consequences of a pandemic and psychological health are significantly worse assessed for the youngest specialists, i.e. those aged 20-29. Not only did they suffer most from the immediate consequences, with psychological health rated significantly worse, but they also had intentions to seek help from psychologists and psychiatrists for the current situation. Older professionals were significantly less likely to report experiencing direct consequences associated with COVID-19. In considering these issues, it should be recalled that the survey took place at the turn of October and November. If the survey had been conducted in early December, we would have obtained even more drastic results. It is not surprising that the change in the feeling of boredom is underestimated - there is never a situation like this. More interestingly, changes in depression are very underestimated by all professionals. Maybe because the concept of depression is more diagnostic than everyday use (like stress, for example).

As many as 9 out of 10 experts agree that the psychological condition of the public has deteriorated as a result of the COVID-19 pandemic. Anxiety, stress, anger, and various fears are identified as the main signs of deterioration (Graph 2).

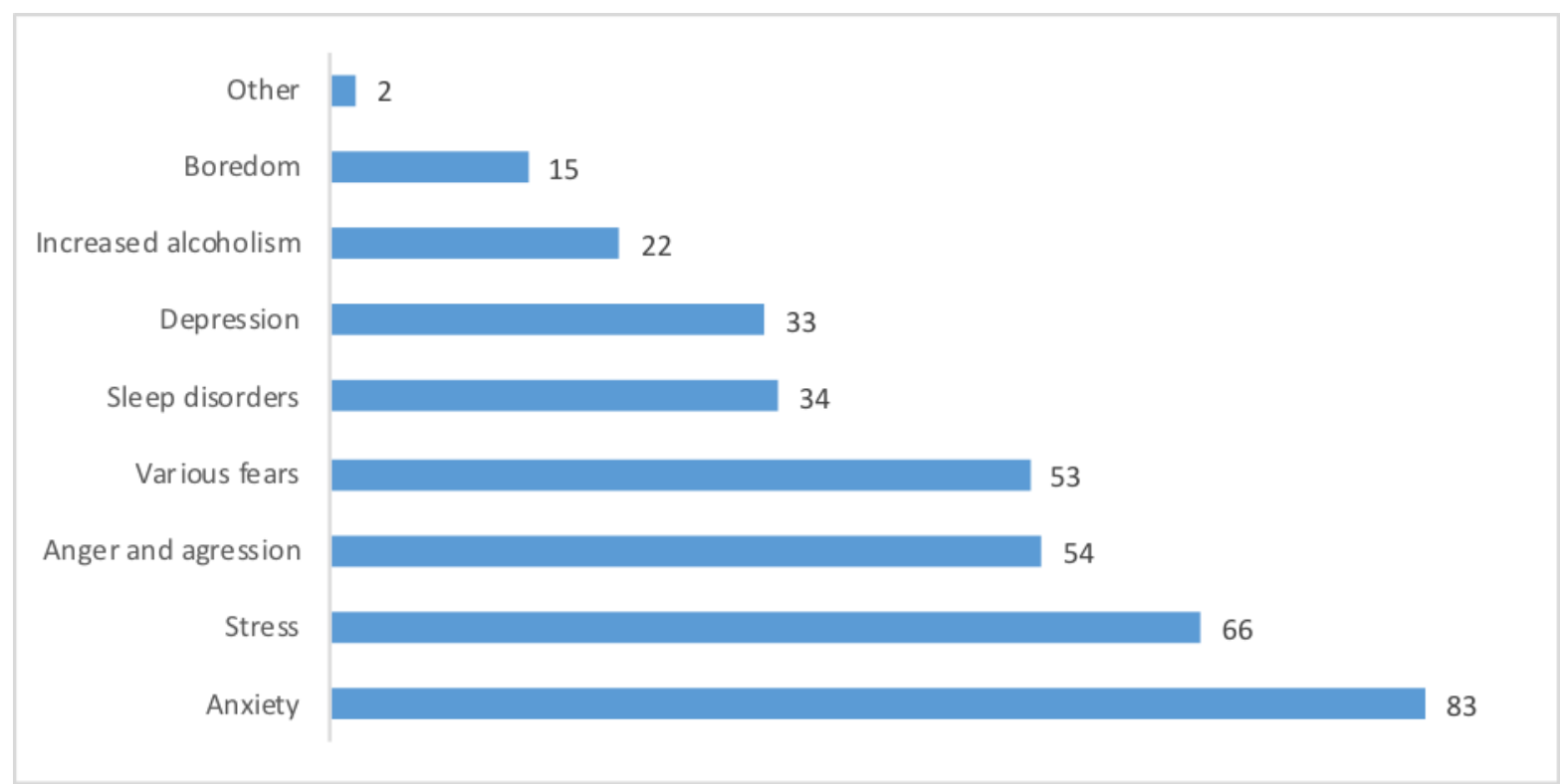

Graph 2. Figures (per cent) of respondents, indicating the course of intensified relevant psychological conditions to ordinary people during the pandemic

Source: compiled by the authors

In terms of psychological services, 4 out of 5 professionals indicated that the need for psychological services in society increased during the pandemic. This need is also more pronounced by younger professionals (20-29 years old) and healthcare professionals.

The assessment of psychological services varies greatly between professionals, with $32 \%$ saying they are difficult to access and $28 \%$ saying they are accessible. Younger professionals (20-29 years old) and health care workers evaluate psychological services the most and indicate the most interventions for changes. Meanwhile, men and older professionals (aged 50-59) are more indifferent to changes in the psychological state and services of society and are less inclined to promote change in this area.

4 out of 5 specialists indicated that the need for psychological services in society increased during the pandemic. This need is also more pronounced by younger professionals 
(20-29 years old) and healthcare professionals. The assessment of psychological services varies greatly between professionals, with $32 \%$ saying they are difficult to access and $28 \%$ saying they are accessible. Younger people value psychological services the most and young people point the most to changes in interventions specialists (20-29 years old) and health care workers.

Meanwhile, men and older professionals (aged 50-59) are more indifferent to changes in the psychological state and services of society and are less inclined to promote change in this area.

In our next study, 240 psychologists were interviewed online using a similar questionnaire. Although they evaluate psychological services and their accessibility more positively, they also quite unanimously propose to change them: 1) to increase accessibility $(60 \%) ; 2)$ to organize them optimally $(40.8 \%) ; 3)$ to develop telepsychology (remote psychological services; 45.8\%); 4) to increase state support in the field of psychological services (75\%). As many as $77.1 \%$ of psychologists are in favor of adopting the Law on Practical Activities of Psychologists.

\section{Conclusions and recommendations}

1. An online survey of physicians, educators, social workers, psychologists and other professionals showed that every second specialist directly felt the consequences of a pandemic, which resulted in changes in income, quarantine or direct exposure to the disease. As a result, the psychological well-being of specialists deteriorated - they felt signs of stress, fear, anxiety, and chronic fatigue.

2. The direct consequences are significantly more frequent for younger professionals: 20-29 year olds, of whom as many as $77 \%$ said they felt the direct consequences of the pandemic. The consequences are also significantly more often felt by health care professionals, who are again directly affected by 3 out of 4 professionals.

3. The other half of the experts state that they do not feel the direct consequences of COVID-19. Direct consequences are significantly less likely to be felt by senior professionals, i.e. those over the age of 60 - 7 out of 10 do not feel the direct consequences. The consequences are also significantly less felt by teachers and pharmacists.

4. 9 out of 10 experts agree that the psychological condition of the public has deteriorated as a result of the COVID-19 pandemic. The main signs of deterioration are anxiety, stress, anger (aggression), specific fears of illness, job loss or loss of income.

5. The following paradox is interesting: although only $9.4 \%$ of professionals used psychological services once or more and only a quarter had physicians, educators and social workers had such intentions, over $80 \%$ of respondents indicated an increased need for psychological services in society.

6. The assessment of psychological services varies greatly among professionals: $32 \%$ say they are difficult to access and 28\% say they are accessible. Younger professionals (20-29 years old) and health care workers and psychologists evaluate psychological services the most and indicate the most interventions for changes. Meanwhile, men and older professionals (aged 50-59) are more indifferent to changes in the psychological state and services of society and are less inclined to promote change in this area.

7. The survey of both - the sample of specialists analyzed in this article and the abovementioned separate sample of psychologists - showed the clear need for psychological services. Summarizing their provisions on the need for psychological services, peculiarities of organization, place of their provision, the following recommendations can be offered to the administrators of psychological services and direct providers working in the private or public sector: 
7.1. The need for psychological services and the intensification of such provision in crisis situations is unquestionable;

7.2 It is necessary to improve the legal regulation of psychological services both at the level of individual agencies and at interdepartmental level;

7.3. The Law on Practical Activities of Psychologists, which has been discussed in the Seimas of the Republic of Lithuania for a whole decade must be adopted and approved as soon as possible;

7.4. It is essential to regulate at least the time norms and costs of psychological services provided in the public sector, as the relevant parameters of health care, social or educational services are regulated;

7.5. Remote psychological services not only for sensitive populations (such as children or silver lines) but also for professionals and the general population (especially in the context of social crises) need to be developed;

7.6. It is advisable to bring university studies of psychologists more in line with the requirements of the EuroPsy diploma.

\section{Acknowledgement}

The authors are thankful to the Research Council of Lithuanian: "Organisational, economic and legal preconditions to optimise psychological support for professionals working in emergency situations" (S-COV-20-23) for financial support to carry out this research.

\section{References}

American Hospital Association. (2020). Hospitals and Health Systems Face Unprecedented Financial Pressures Due to COVID-19. Retrieved from: https://www.aha.org/guidesreports/2020-05-05-hospitals-and-health-systems-faceunprecedented-financial-pressures-due

Bolino, M. (2020). Managing Employee Stress and Anxiety during the Coronavirus. Retrieved from: https://www.psychologytoday.com/us/blog/the-thoughtfulmanager/202003/managing-employee-stress-and-anxiety-during-the-coronavirus

Cabarkapa, S., Nadjidai, S. E., Murgier, J., \& Ng, C. H. (2020). The psychological impact of COVID-19 and other viral epidemics on frontline healthcare workers and ways to address it: a rapid systematic review. Brain, Behavior and Immunity - Health, 8, 100144. doi: 10.1016/j.bbih.2020.100144

Cawcutt, K. A., Starlin, R., \& Rupp, M. E. (2020). Fighting fear in healthcare workers during the COVID-19 pandemic. Infection Control \& Hospital Epidemiology, 25. 1-2. doi: 10.1017/ice.2020.315

Chan, A. O. M. \& Huak, C. Y. (2004). Psychological impact of the 2003 severe acute respiratory syndrome outbreak on health care workers in a medium size regional general hospital in Singapore. Occupational Medicine, 54(3), 190-196. doi: https://doi.org/10.1093/occmed/kqh027.

Chen, Q., Liang, M., Li, Y., Guo, J., Fei, D., Wang, L., He, L., Sheng, C., Cai, Y., Li, X., Wang, J., Zhang, Z. (2020). Mental health care for medical staff in China during the COVID-19 outbreak. Lancet Psychiatry, 7(4), e15-e16. doi: 10.1016/S22150366(20)30078-X.

Dementiev, E.V. (2021). Why Countries Differ Greatly in the Effects of COVID-19, Montenegrin Journal of Economics, 17(4), 55-63. 
Dias, R., Teixeira, N., Machova, V., Pardal, P., Horak, J., \& Vochozka, M. (2020). Random walks and market efficiency tests: evidence on US, Chinese and European capital markets within the context of the global Covid-19 pandemic. Oeconomia Copernicana, 11(4), 585-608. https://doi.org/10.24136/oc.2020.024.

Du, J., Dong, L., Wang, T., Yuan, C., Fu, R., Zhang, L., Liu, B., Zhang, M., Yin, Y., Qin, J., Bouey, J., Zhao, M., \& Li, X. (2020). Psychological symptoms among frontline healthcare workers during COVID-19 outbreak in Wuhan. General Hospital Psychiatry, S0163-8343(20), 30045-1. Retrieved from: https://www.ncbi.nlm.nih.gov/pmc/articles/PMC7194721/pdf/main.pdf

Gayer-Anderson, C., Latham, R., El Zerbi, C., Strang, L., Moxham Hall, V., Knowles, G., Marlow, S., Avendano, M., Manning, N., Das-Munshi, J., Fisher, H., Rose, D., et al. (2020). Impacts of social isolation among disadvantaged and vulnerable groups during public health crises. Retrieved from: https://esrc.ukri.org/files/news-events-andpublications/evidence-briefings/impacts-of-social-isolation-among-disadvantaged-andvulnerable-groups-during-public-health-crises/

Gupta, S., Sahoo, S. (2020). Pandemic and mental health of the front-line healthcare workers: a review and implications in the Indian context amidst COVID-19. General Psychiatry, 33(5), e100284. doi: 10.1136/gpsych-2020-100284

Humer, E., Pieh, C., Kuska, M., Barke, A., Doering, B. K., Gossmann, K., Trnka, R., Meier, Z., Kascakova, N., Tavel, P., \& Probst, T. (2020). Provision of Psychotherapy during the COVID-19 Pandemic among Czech, German and Slovak Psychotherapists. International Journal of Environmental Research and Public Health, 17(13), 4811. doi: 10.3390/ijerph17134811

Inchausti, F., MacBeth, A., Hasson-Ohayon, I., \& Dimaggio, G. (2020). Psychological Intervention and COVID-19: What We Know So Far and What We Can Do. Journal of Contemporary Psychotherapy, 27, 1-8. doi: 10.1007/s10879-020-09460-w

Javadi, S. M. H., Arian, M., \& Qorbani-Vanajemi, M. (2020). The need for psychosocial interventions to manage the coronavirus crisis. Iranian Journal of Psychiatry and Behavioral Sciences, 14(1), e102546. doi: 10.5812/ijpbs.102546

Jiang, X., Deng, L., Zhu, Y., Ji, H., Tao, L., Liu, L., Yang, D., \& Ji, W. (2020). Psychological crisis intervention during the outbreak period of new coronavirus pneumonia from experience in Shanghai. Psychiatry Research, 286. https://doi.org/10.1016/j.psychres.2020.112903

Kufel, T. (2020). ARIMA-based forecasting of the dynamics of confirmed Covid-19 cases for selected European countries. Equilibrium. Quarterly Journal of Economics and Economic Policy, 15(2), 181-204. https://doi.org/10.24136/eq.2020.009

Lai, J., Ma, S., Wang, Y., Cai, Z., Hu, J., Wei, N., et al. (2020). Factors associated with mental health outcomes among health care workers exposed to coronavirus disease 2019. JAMA Network Open, 3, e203976. doi: 10.1001/jamanetworkopen.2020.3976

Liu, S, Yang, L, Zhang, C, Xiang, Y-T, Liu, Z, Hu, S, et al. (2020). Online mental health services in China during the COVID-19 outbreak. Lancet Psychiatry, 7(4), e17-e8. doi: https://doi.org/10.1016/S2215-0366(20)3007

Lu, W, Wang, H, Lin, Y, \& Li, L. (2020). Psychological status of medical workforce during the COVID-19 pandemic: a cross-sectional study. Psychiatry Research, 288, 112936. doi: https://doi.org/10.1016/j.psychres.2020.112936.

Mihalca, L., Lucia Ratiu, L., Brendea, G., Metz, D., Dragan, M., \& Dobre, F. (2021). Exhaustion while teleworking during COVID-19: a moderated-mediation model of role clarity, self-efficacy, and task interdependence. Oeconomia Copernicana, 12(2), 269306. https://doi.org/10.24136/oc.2021.010 
Nyashanu, M., Pfende, F., \& Ekpenyong, M. (2020). Exploring the challenges faced by frontline workers in health and social care amid the COVID-19 pandemic: experiences of frontline workers in the English Midlands region, UK. Journal of Interprofessional Care, 34(5), p. 655-661. https://doi.org/10.1080/13561820.2020.1792425

Pardal, P., Dias, R., Šuleř, P., Teixeira, N., \& Krulický, T. (2020). Integration in Central European capital markets in the context of the global COVID-19 pandemic. Equilibrium. Quarterly Journal of Economics and Economic Policy, 15(4), 627-650. https://doi.org/10.24136/eq.2020.027

Shechter, A., Diaz, F., Moise, N., Anstey, D. E., Ye, S., Agarwal, S., Birk, J. L., Brodie, D., et al. (2020). Psychological distress, coping behaviors, and preferences for support among New York healthcare workers during the COVID-19 pandemic. General Hospital Psychiatry, 66, 1-8. doi: 10.1016/j.genhosppsych.2020.06.007

Smith, E. (2020). How to support staff mental health during a crisis. Retrieved from: https://www.devex.com/news/how-to-support-staff-mental-health-during-a-crisis-96979

Solomon-Osborne, A. (2020). Opinion: psychological first aid for front-line workers in quarantine. Retrieved from: https://www.devex.com/news/opinion-psychological-firstaid-for-front-line-workers-in-quarantine-98239

Tasnim, S., Hossain, M. M., \& Mazumder, H. (2020). Impact of rumours or misinformation on coronavirus disease (COVID-19) in social media. Journal of Preventive Medicine and Public Health, 53(3), p. 171-174. doi: 10.3961/jpmph.20.094

Tomlin, J., Dalgleish-Warbuton, B., \& Lamph, G. (2020). Psychosocial Support for Healthcare Workers during the COVID-19 Pandemic. Retrieved from: https://www.frontiersin.org/articles/10.3389/fpsyg.2020.01960/full

Unicef. (2020). Protecting Salaries of Frontline Teachers and Health Workers. Retrieved from:

https://www.unicef.org/socialpolicy/files/Protecting_Salaries_of_Frontline_Teachers_a nd_Healthcare_Workers_final(1).pdf

Vasylieva, N. (2021). "Food Security in Times of Covid-19: Price Aspects in Ukraine and Neighboring EU Countries", Montenegrin Journal of Economics, 17(3), pp. 21-30.

Vizheh, M., Qorbani, M., Arzaghi, S. M., Muhidin, S., Javanmard, Z., \& Esmaeili, M. (2020). The mental health of healthcare workers in the COVID-19 pandemic: a systematic review. Journal of Diabetes and Metabolic Disorders, 26, 1-12. doi: 10.1007/s40200020-00643-9.

World Health Organisation. (2020). Frontline workers and COVID-19: coping with stress. Retrieved from: http://www.emro.who.int/mnh/news/frontline-workers-and-covid-19coping-with-stress.html

Xiao, H., Zhang, Y., Kong, D., Li, S., \& Yang, N. (2020). The Effects of Social Support on Sleep Quality of Medical Staff Treating Patients with Coronavirus Disease 2019 (COVID-19) in January and February 2020 in China. Medical Science Monitor, 26. doi: 10.12659/ MSM.923549

Xiaoming, X., Ming, A., Su, H., Wo, W., Jianmei, C., Qi, Z., Hua, H., Xuemei, L., Lixia, W., Jun, C., Lei, S., Zhen, L., et al. (2020). The psychological status of 8817 hospital workers during COVID-19 Epidemic: A cross-sectional study in Chongqing. Journal of Affective Disorders, 276, 555-561. doi: 10.1016/j.jad.2020.07.092

Zhang, W., Wang, K., Yin, L., Zhao, W., Xue, Q., Peng, M., Min, B., Tian, Q., Leng, H., Du, J., Chang, H., Yang, Y., et al. (2020). Mental Health and Psychosocial Problems of Medical Health Workers during the COVID-19 Epidemic in China. Psychotherapy and Psychosomatics, 9, 1-9. doi: 10.1159/000507639 
Zhou, X. (2020). Psychological crisis interventions in Sichuan Province during the 2019 novel coronavirus outbreak. Psychiatry Research, 286. doi: 10.1016/j.psychres.2020.112895

Zinecker, M., Doubravský, K., Balcerzak, A.P., Pietrzak, M. B., \& Dohnal, M. (2021). The Covid-19 Disease and Policy Response to Mitigate the Economic Impact in the EU: An Exploratory Study Based on Qualitative Trend Analysis. Technological and Economic Development of Economy, 27(3), 742-762. doi: https://doi.org/10.3846/tede.2021.14585 